\title{
An Experience with Patients with Venous Thromboembolism at Sir Ganga Ram Hospital, Lahore
}

\author{
A NAZEER B SHABIR A KAMAL A KAMAL S QAISERA \\ Department of Medicine, Fatima Jinnah Medical College/Sir Ganga Ram Hospital, Lahore. \\ Correspondence to Dr.Asma Nazeer,Assistant Professorasma_mir04@hotmail.com
}

Venous thromboembolism is responsible for substantial morbidity and mortality if left unsuspected especially in the presence of certain risk factors. The purpose of our study was to review patients of deep vein thrombosis regarding the underlying risk factors, its complications, treatment and outcome. Our study at Sir Ganga Ram Hospital, Lahore consisted of 56 patients out of which $42(75 \%)$ were females. The presence of Deep vein thrombosis was confirmed by venous ultrasonography. Various risk factors were identified in $45(80.3 \%)$ patients. All patients were given LMWH in initial phase followed by warfarin. Clinical response was monitored for period of three months. Two patients $(10 \%)$ develop gastrointestinal bleeding as complication of therapy. Three patients $(5.35 \%)$ died of pulmonary embolism. Early recognition of disease and its complication along with timely treatment and adequate follow up can reduce morbidity and mortality.

Key words: VTE: Venous thromboembolism, DVT: Deep Vein thrombosis, PE: Pulmonary Embolism, LMWH: Lower Molecular weight heparin

DVT affects 800,000 new patients per year ${ }^{1}$. The incidence is increases with $\mathrm{age}^{2}$. It can endanger life when complicated by pulmonary embolism. Both. DVT and pulmonary embolism are frequently not suspected clinically resulting in significant diagnostic and therapeutic delays which account for substantial morbidity and mortality. DVT occurs in a variety of clinical conditions with underlying pathogenesis of venous stasis, venous injury and hypercoaguability. Frequently more than one risk factor is present. Knowledge of these provides rationale for both prophylaxis and clinical suspicion. Sometimes it develops without obvious provocation (idiopathic). These patients may have either inherited or acquired thrombophilia or biochemical genetic abnormality.

The objective of our study is to find out underlying risk factors related to VTE, complications of the disease, treatment response and therapy related side effects in our patients.

\section{Material and methods}

The study was conducted at Medical Unit-II, Sir Ganga Ram Hospital Lahore, during year 2003. All patients with clinical suspicion of DVT (as illustrated in table 1) confirmed by venous ultrasonography were included in the study. Three patients developed breathlessness and pulmonary embolism was suspected. Chest X-ray, ECG and Ventilation Perfusion Scan were carried out in these patients.

Other appropriate tests including chest X-ray, ultrasonography, haematological evaluation of hypercoaguability were done to assess underlying risk factors. Anticoagulant therapy LMWH in dosage of 1 $\mathrm{mg} / \mathrm{kg} / 12$ hrs was instituted in all patients with DVT. Patients with pulmonary embolism received UFH in dosage of 30,000 units/days. Later oral warfarin was continued for period of three months with monitoring of
INR before and during therapy. Response to therapy, outcome and side effects were also monitored.

\section{Results}

Fifty six patients were included in the study. Forty two $(75 \%)$ of them were females. Mean age of the patients was 40-60 years. Risk factors were identified in $45(80.3 \%)$ patients, the distribution of these are shown in Table 1.

Venous ultrasonography with doppler flow assessment in all patients revealed thrombosis of proximal vein extending to femoral vein in $80 \%$ cases. Popliteal vein thrombosis was seen in $20 \%$ case.

Table 1: Base line characteristics of Patients with venous thrombolism $(n=56)$

\begin{tabular}{ll}
\hline Characteristics & $\begin{array}{l}\text { No. of patients } \\
(\%)\end{array}$ \\
\hline Age & \\
$20-40$ years & $14(25)$ \\
$40-60$ year: & $42(75)$ \\
Sex $\quad$ Female & $42(75)$ \\
Male & $14(25)$ \\
Clinical features & \\
Leg pain & $56(100)$ \\
Leg Swelling & $56(100)$ \\
Tenderness & $48(85.7)$ \\
Associated Conditions & $7(12.5)$ \\
- Pregnancy & $7(12.5)$ \\
- Postpartum state & $6(10.7)$ \\
$\quad$ Taking oral contraceptive & $\&$ \\
- Immobility & $6(10.7)$ \\
- Malignant diseases & $12(21.7)$ \\
- Inherited coagulopathies & $6(10.7)$ \\
\hline
\end{tabular}

Institution of LMWH in early phase and subsequent warfarin therapy resulted in clinical improvement in term 
of pain, swelling and tenderness in all patients with deep vein thrombosis. Three patients with clinical diagnosis of pulmonary embolism were confirmed by ECG, X-ray and ventilation perfusion scan. They were put on unfractionated heparin. Gastrointestinal bleeding occurred in two patients. Three patients died of pulmonary embolism during the study.

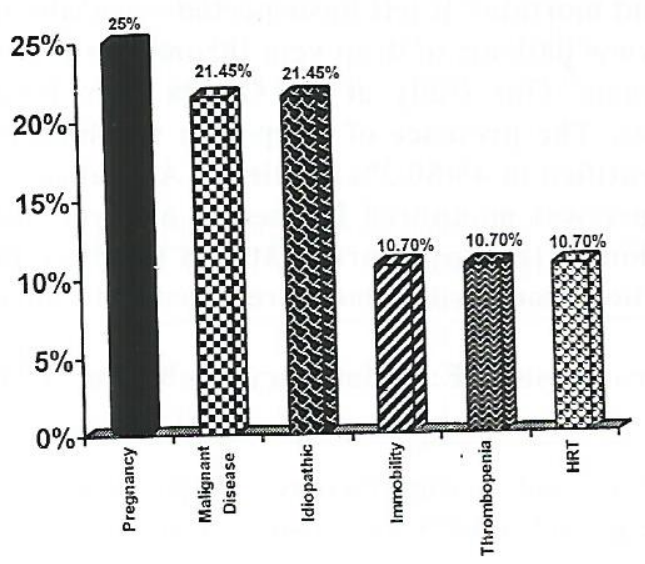

Fig-1: Distribution of Risk Factors among out patients: $(n=56)$

\section{Discussion}

Our study showed that VTE occurs in the setting of multiple underlying risk factors in $80 \%$ cases or shown in Table 1 and Fig. 1 .

Cause could not be determined in $20 \%$.

Female preponderance is observed is varies studies (3). Our study also showed that majority of on patients were females, $(75 \%)$, females to male ratio being $3: 1$ as compared to $4: 3$ in other reports ${ }^{3}$. This difference is due to the fact that $35 \%$ of our patients were referred to us from Obstetrics and Gynaecology Department, this department constituted a major proportion (52\%) of total admissions in our hospital during the year 2003 . Seven $(12.5 \%)$ of our patients were pregnant, the remaining $7(12.5 \%)$ presented in the postpartum period. This observation is in concordance with other studies which states that incidence of VTE is higher pregnancy and postpartum period than in non pregnant ${ }^{4,5}$.

Six $(10 \%)$ patients were taking oral contraceptives/estrogen which have proved to be significant etiological factor in VTE. They were taking estrogen therapy for the last one-year. In clinical trials evaluating estrogen therapy it appears that an annual total of 16.5 cases of VTE out of 100,000 individuals may be attribute to hormone replacement therapy ${ }^{6}$. Risk is highest in first year of exposure to hormone replacement ${ }^{7}$. Past use may not increase the risk ${ }^{8}$.

Six $(10.7 \%)$ of our patient had DVT following immobility due to stroke (3), paraplegia (2) and fracture neck of femur (1). This observation is supported by similar reports ${ }^{9}$.

Malignant diseases were found in 12 patients $(21.4 \%)$ of our study group. Ovarian CA was found in 6 and breast CA was associated with DVT in 3 patients. Rest of the three had bronchogenic CA. Three of these patient develop $\mathrm{PE}$ and none survived. These result from our study parallel those of the Prospective Investigation of Pulmonary Embolism Diagnosis (PIOPED) trial which revealed that $18.3 \%$ of patient with malignant diseases developed $\mathrm{PE}^{10}$. Varies factors are through to play a role in the pathogenesis of VTE in malignancy including thrombophilia, decreased ambulation, chemotherapy induced neutropenia and sepsis ${ }^{11}$.

Inherited coagulopathies increase the tendency towards VTE ${ }^{(12)}$ we also found 6 patients $(10.7 \%)$ with protein $\mathrm{C}$ deficiency and protein $\mathrm{S}$ deficiency. The screening was helpful for diagnosis and prevention of complications of the disease. These patients require longterm management. More recently other factors like mutation in prothrombin gene $(\mathrm{G} 20210 \mathrm{~A})$ and factor 5 has been identified which are common healthy whites but rare among Asians and Africans ${ }^{13}$. Identification of these gene mutation would be helpful in diagnosis of those cases which are labeled as idiopathic. In 12 patients (12.4\%), no laboratory, radiological and other evidences could identify the cause.

Diagnostic techniques use for confirmation of DVT in our patients was compression ultrasonography which has been found sensitive and specific for symptomatic DVT in $90 \%$ cases $^{14,15}$. Besides non-invasive it is also cheaper. More over it detects proximal vein thrombosis with great accuracy ${ }^{16}$

Three patients who had PE was confirmed by ventilation perfusion scan which, showed ventilation perfusion mismatch.

MRI, and Spiral CT scan and other latest modalities used for confirmation of DVT and PE respectively ${ }^{17-19}$ but financial restraint limited their use in our study.

We managed all our patients with LMWH in the initial treatment in the dose of $1 \mathrm{mg} / \mathrm{kg} / 12$ hourly. It was found to be quite effective and safe; on observation which is in confirmation meta-analysis ${ }^{20-23}$

\section{Recommendations}

Early recognition of possible risk tactors is important for prevention of VTE and prophylaxis is recommended. Risk factors once identified in patients with established DVT treatment to reduce the morbidity and mortality associated with the diseases. Complications of the disease and its treatment should be carefully watched for and treated as early as possible. Stress should be laid on long term treatment and follow up in order to reduce the rate of recurrence of the condition. 


\section{References}

1. Hirsh J and Agnes YY Lee; How we diagnose and treat deep vein thrombosis. Blood 2002;99:3102-3110

2. Egermayer P. Silent pulmonary embolism. Arch Intern Med. 2000; 160:2218

3. Thomas DP et al Hypercoaguability in venous and arterial thrombosis Ann Intern Med 1997; 337:657

4. MR, Weg JG. Current concepts: Venous thromboembolism during pregnancy N Engl J Med 1996; 335:108

5. Bryan S. Jick MD. Editorial OBGYN News May 15, 2001

6. Daly E, Vessey MP, Hawkins MM et al. Risk of Venous thromoboembolism in users of hormone replacement therapy. Lancet 1996; 348:981

7. Jick H, Derby LE, Myers MW et al. Risk of hospital admission for idiopathic venous thromboembolism among users of post menopausal estrogen. Lancet 1996; 348:981

8. Grodstein F. Stamper MJ, Gold Laber SZ, et al. Prospective study of exogenous hormones and risk of pulmonary embolism in women Lancet 1996: 348:983

9. Lamb GC, Tomski MH, Kanfman J et al. Is chronic spinal cord injury associated with increased risk of venous thromboembolism. J Am Paraplegia Soc 1993; 16:153

10. Carson JL, Kelly MA, Duffy A, et al. The clinical course of pulmonary embolism. N Engl J Med 1992; 326:1

11. Pineo GP, Brain MC, Gallns AS et al. Tumors, mucus production and hypercoagulibility. Ann NY Acad Sci 1974; 230:262

12. Ida Martinelli, Pier Mannuccio Mannucci et al. Different risks of thrombosis in four coagulation defects associated with inherited thrombophilia: A study of 150 families. Blood 1998:92:2353-2358.

13. Selingsohnn U, Lubetsky A, Genetic susceptibility to venous thrombosis. N Eng J Med 2001; 344:1222

14. Clive Kearon et al Non-invasive diagnosis of deep vein thrombosis. Ann Intern Med 1998;128:663-675
15. Anderson DR, Lensing AWA, Wells PS, et al. Limitation of impedance plethesmography in the diagnosis of clinically suspected deep vein thrombosis. Ann Intern Med 1993: 118:25

16. Lensing AW, Levi MM. Buller HR et al. Diagnosis of deep vein thrombosis using a objective Doppler method. Ann Intern Med 1990; 113:9

17. Even AJ, Tapson VF, Sostman HD et al. The diagnosis of deep vein thrombosis. A prospective comparison of Venography and Magnetic Resonance Imaging Chest 1992: 102:120S

18. Remy Jardin M, Rany J. Wattine L. Girand F. Central pulmonary thromboembolism diagnosis with spiral Volumetric CT with the single breath hold technique. Comparison with pulmonary angiography. Radiology 1992;185:381.

19. Goodman LR, Curtin JJ, Mewissen MW, et al. Detection of pulmonary embolism in patients with unresolved clinical and scintigraphic diagnosis: helical CT versus angiography AJR Am J Roentgenol 1995;164:1369.

20. Dolovick LR, Ginsberg JS, Douketis JD, et al. A metaanalysis comparing low molecular weight heparin with unfractionated heparin in the treatment of venous thromboembolism Arch. Intern Med 2000. 160:181.

21. Siragusa S, Cosmi B, Piovella F et al. Low molecular weight heparins and infractionated heparin in treatment of venous thromboembolism. Am J Med 1996;100:269.

22. Leizorovicz A, Simonneau G, Decousus H, Biossel JP Comparison of efficacy and safety of low molecular weight heparins and infractionated Heparin in initial treatment of deep venous thrombosis. BMJ 1994:309:299.

23. Lensing AWA. Prins MH, Davidson BL. Hirsh J. Treatment of deep venous thrombosis with low molecular weigh heparins: and metaanalysis. Arch Inter Med 1995;155;601 